\title{
SOLAR TRACKING STAND FOR SOLAR PANELS AND COLLECTORS
}

\author{
Henriks Putans, Imants Ziemelis, Ilze Pelece, Andrejs Snegovs \\ Latvia University of Life Sciences and Technologies, Latvia \\ henriksooo@inbox.lv,imants.ziemelis@1lu.lv,ilze.pelece@1lu.lv, andrejs.snegovs@gmail.com
}

\begin{abstract}
The conversation of solar energy into electricity using photovoltaic panels and into heat energy using solar collectors is the challenge of the time. Presently widely used fossil energy is unfriendly to the earth environment and its amount is limited. Both solar panels and solar collectors produce more energy, if direct solar radiation strikes its working surface perpendicularly during all the operation time. For that special device - the sun tracking stands or trackers, automatically keeping their working surface perpendicular to the sunbeams, are used. Different constructions of solar trackers and actuators are known: trackers based on the clockwork principle, based on the principle of freon evaporation and condensation, based on the principle of spring made of shape-memory alloys and others. The trackers act on a control unit and actuator, changing the position of the panels or collectors in azimuth, or azimuth and zenith plane. Different constructions of the actuators are in operation. Driving mechanisms with one electric motor (turning only in one plane) or with two electric motors (turning in two planes) are widely used. In the Ulbroka Research Centre a solar tracking stand of a new construction has been developed. There only one electric motor with a gearbox and a crank mechanism simultaneously is turning solar panels in two planes (Latvia patent LV 15245 A, 2017). The device has been made, experimentally investigated in field conditions on the roof of a house and positive results have been obtained. The amount of electric energy produced by two solar panels placed on the developed stand during the summer time of 2017 has been compared with the gain of electricity produced by in the same conditions working stationary fixed panels of the same type. Tracking the sun panels had produced around 1.48 times more electric energy than the fix ones, but in September 1.3 times more.
\end{abstract}

Keywords: photovoltaic, panels, electricity, trackers.

\section{Introduction}

There are many possibilities of the use of solar energy. One of them is the use it for production of heat and electricity. The conversion of solar energy into electricity using photovoltaic panels and into heat energy using solar collectors can help decrease the consumption of fossil energy, which is widely used up to date but is unfriendly to the earth environment. The technology for production of heat energy from sunlight has been known and used long time ago. The transformation of solar energy into electricity is another possibility to use it for practical needs. The main task of the technology used for both transformations is to do it with as high as possible efficiency and low costs. Solar energy in that way is widely used in many countries all over the globe, particularly in Southern countries and large amount of international experience is collected [1].

Solar panels and collectors produce more energy, if direct solar radiation strikes the working surface perpendicularly during the whole operation time [2]. On cloudy days, if there is no direct radiation, the system automatically has to be oriented to the clouds reflecting the direct solar radiation. For that, special devices - the sun tracking stands with trackers, automatically keeping the radiation absorbing surface perpendicular to sunbeams, are used. Different constructions of solar trackers and actuators have been designed and are operating in practice [3]. There are trackers based on the clockwork principle. They can operate under any weather conditions, even in the dark also. Trackers based on the principle of freon evaporation and condensation are simple by construction, but their tracking precision is lower. Trackers based on the principle of the spring made of shape-memory alloys, for example, nickel-titanium, are striving to take its initial form and another construction of the trackers. These constructions are complicated and expensive. Some of them have been successfully working only in laboratory conditions. Solar tracking devices have to be able to work in changing meteorological conditions, like different temperature, rain and snow, formation of ice, changing air humidity and withstand the mechanical impact of wind forces, hailstones, thunder storms, contact with animals etc.

By means of a control unit, the tracker acts on the actuator changing the position of the panel or collector orientation in azimuth, or in azimuth and zenith plane. The design of actuators operating in practice can be very different [4]. The objective of the research is to make the construction of the solar tracking stand simpler using only one electric motor. 


\section{Materials and methods}

The developed device (collar tracking stand URC) is in two axes automatic solar tracking stand with single motor drive. It has been anticipated for domestic application, producing electricity, if mounted with solar panels, or hot domestic water, if mounted with solar panels. In our experimental investigation two solar photovoltaic panels (Gs-50, a-Si, $50 \mathrm{~W}$ ) are used.

The developed solar tracking stand URC in this research has been compared with a two axes solar tracking device ST44M2V4Pproduced by industry and having two linear electric motors SM4S520M2US, mounted on a frame. The motors, changing the length of their push bars in relation to the post, turn the frame with panels to the sun in vertical (zenith) and horizontal (azimuth) plane (Fig. 1).

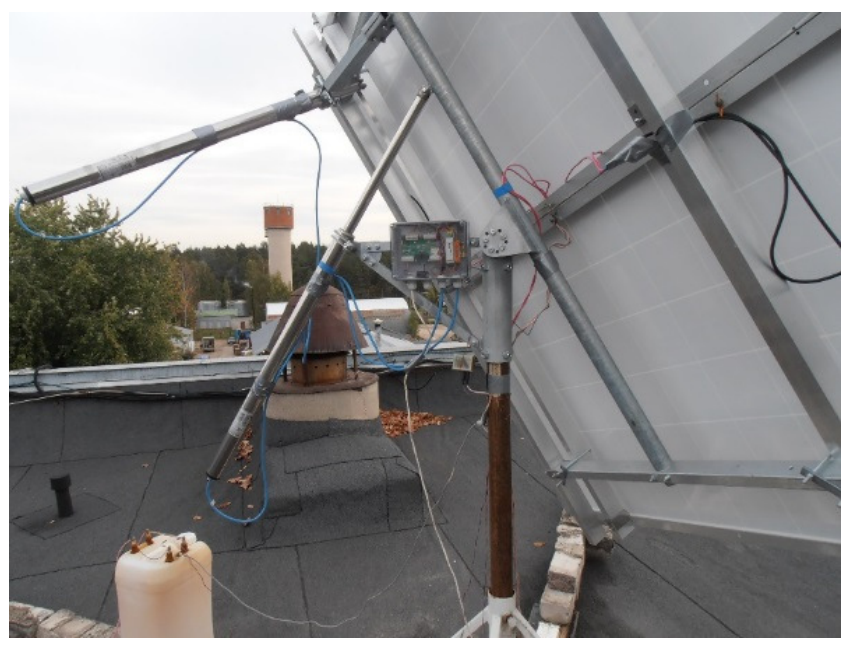

Fig. 1.Solar tracking device ST44M2V4P with twopush bars and two solar photovoltaic panels Solet P6.60-WF-250

The device ST44M2V4P has a control unit "Sat Control", four solar photovoltaic panels Solet P6.60-WF-250 and four solar micro-inventers Enphase M215. Total power of the appliance is $1.0 \mathrm{~kW}$, active absorber`s area $-7.7 \mathrm{~m}^{2}$. There can be 4 or $8 \mathrm{PV}$ panels mounted on the stand. The anticipated power produced by the device can be one or two kW accordingly. The developed solar panels tracking stand URC (Fig.2) is a zenith-azimuth stand variety, where in order to simplify the construction only one electric motor is used. The device turns mounted on the stand a solar energy receiver in the azimuth plane, but another - zenith motor has been replaced by a passive element.

Design features. The device (Fig. 2) consists of a vertical post 1 supported on the floor and having a motor-gearbox 2 on its upper end. The gearbox is powered by a voltage polarizing $12 \mathrm{~V}$ direct current electric motor. On the upper end of the vertical (secondary) shaft of the gearbox, a loudbearing box 3 with horizontally positioned bearings fitted with a horizontal shaft 4 is assembled.

On the horizontal shaft, the panels 9 and 10 are fixed. In the bearing box, the horizontal shaft has an axial movement limiter, as well as an axial and radial motion limiting clutch plate. The device is specific with the construction peculiarity that changing the panels' angle in the azimuth plane accordingly the panels' angle in the zenith plane is changing. On the vertical post of the device a holder 7 directed to the south with a ball joint 8 on its free end is fixed. In the middle of the horizontal shaft 4 , with a clamping tape, a zenith angle-shaped knob 5 having a ball joint on its free end has been placed. Both ball joints are connected with a connecting rod 6 . When the clutch is engaged (in working condition), the clutch is fixedly connected to the horizontal shaft to the horizontal (azimuth) plane along with the horizontal shaft and the solar panels. At the same time, the connecting rod pushes the knob up or pulls down and along with the horizontal shaft the solar panels in the zenith plane.

Zenith angle change manual gearbox. During the year, the angle of incidence of sunlight changes in relation to the horizon, due to the sun's declination angle $\pm 23^{\circ} 27^{\prime}$ [3]. In order to minimize the effect of the declination angle on the accuracy of the orientation of the solar panels, the device has been intended periodically annually to rotate the horizontal shaft and correct the position of the panels in the zenith plane. 


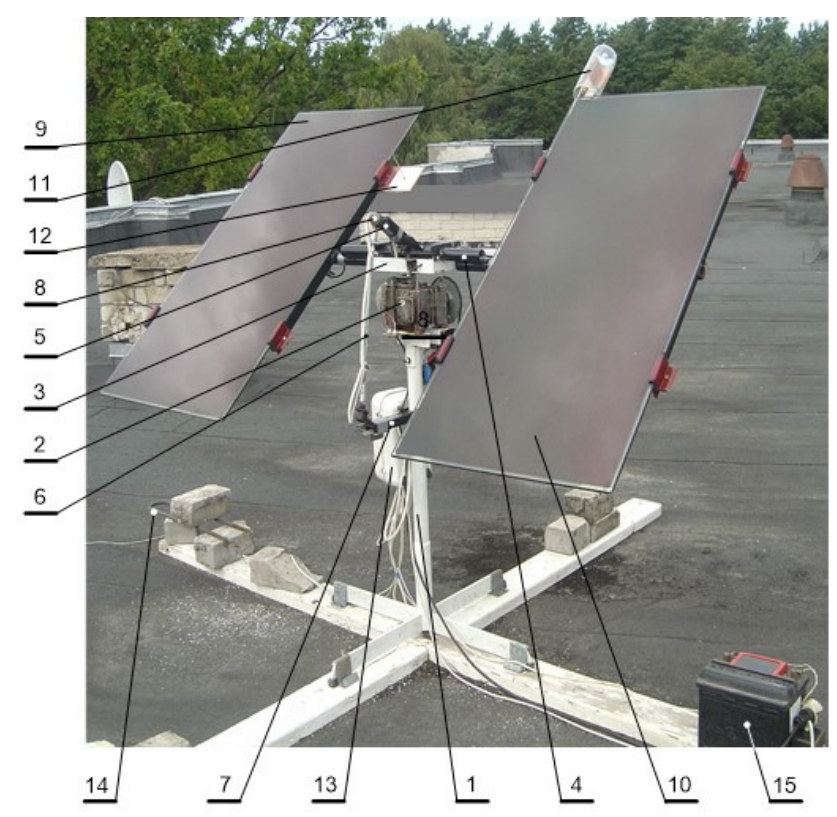

Fig.2. Overview of sun tracking stand URC: 1 - post; 2 - electric motor with gearbox; 3 - carrier box; 4 - horizontal shaft; $5 ; 6 ; 7$ - zenith angle shaping elements (5 - crank; 6 - connecting rod); 7 - bracket; 8 - swivel; 9; 10 - solar panels (Gs,-50, a-Si, $50 \mathrm{~W}$ ); 11 - solar sensor; 12 - solar radiation direction indicator; 13 - control and automatic devices box; 14 - electricity consumer

(TENs); 15 - electric battery

Panel switching end switch. In order to prevent damage to the device due to the permissible rotational angles of the panels, the device has been equipped with an azimuthal rotational limiting electro-mechanical terminal switch (Fig.3), which operating range is changing according to the solar panel angle setting. This is achieved by attaching the end switch to the loud-bearing box, but its unlocking lever placed on the horizontal shaft. By changing the zenith angle of the solar panel surface normal relative to the horizon, the range of angles of rotation in the azimuth plane also changes. In order to be able to start the drive after turning off (turn in the opposite direction), the opposite polarity voltage must be applied to the drive motor. This is done by the power switch, which is fixed on the gear housing, but the switching sector on the gear secondary shaft.

Operation in automatic mode. A solar sensor (Fig. 2; Fig.4) and a night sensor, a photo resistor placed in the control and automation device box (Fig.1.) have provided that in the automatic mode the working surface is facing down through the box (window). The use of a solar sensor makes PV devices an autonomous, self - orientating solar panel. Solar sensor infrared diodes capture solar radiation; convert it to electricity that generates voltage that goes through the amplifier to the drive motor terminals.
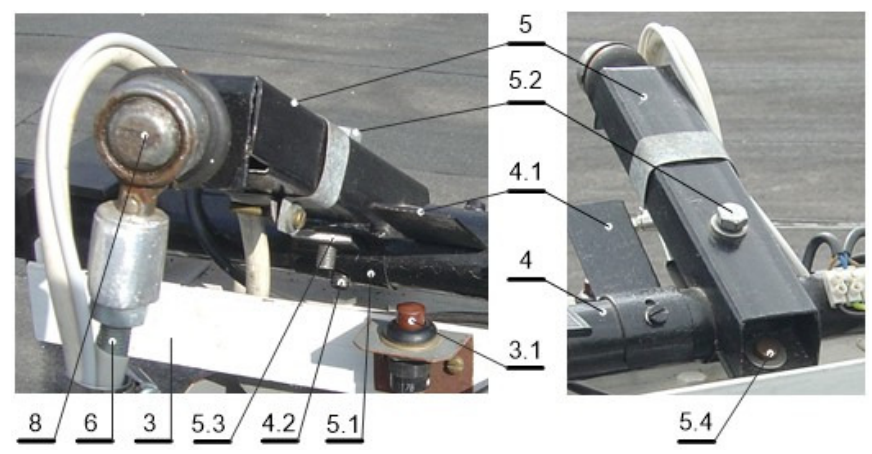

Fig. 3. Zenith angle manual modification mechanism and azimuth angle end switch:

3 - load carrier box; 4 -horizontal shaft; 5; 6; 7 - zenith angle shaping elements (5 - knob, 6 - connecting rod, 7 - bracket); 8 - swivel; 3.1 - end switch; 4.1 - end switch release lever;

4.2 - clampingbelt fixation pin; 5.1 - clutch board; 5.2 - clutch shift screw; 5.3 - nut; 5.4 - clamping bolt mounting screw 
The solar sensor is symmetrical, bi-directional, has a western and eastern side (Fig. 5). The device's performance controller has been designed so that, if both sides of the sensor receive the same intensity of solar radiation, then the voltage on the motor terminals is zero, but there are different intensities than the voltage on the motor terminals, that of the panels on the heavily irradiated side. The cutting continues until the intensity of the solar radiation on both sides has aligned (radiation becomes perpendicular to the surface of the panels) and the motor stops because the power supply voltage disappears. As the sun moves toward the west, the west side of the sensor increases. By reaching the specific intensity limit, the engine switches on and rotates the panels to the west until the irradiation on both sides of the sensor has aligned. This process will continue throughout the day to day, when the solar sensor no longer receives radiation and the device stops functioning. When entering darkness the night (dark) sensor, the voltage of the corresponding polarity, is applied to the motor, which rotates the PV panels eastwards or southwards (depending on the setting). When exposed to the sun, the solar sensor starts to receive radiation and the process under review continues.

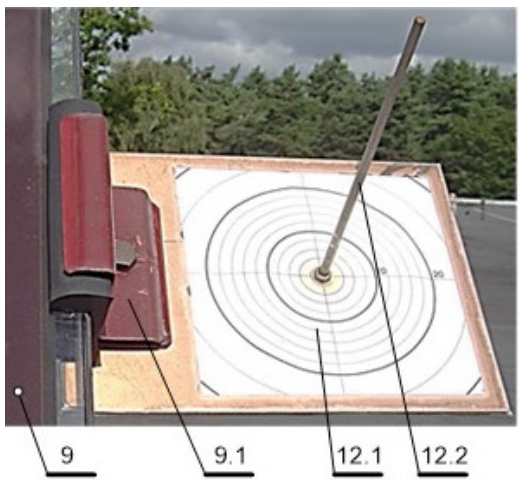

Fig. 4. PV solar radiation indicator light sensor: 9 - solar panel; 9.1 - solar panel assembly unit; 12.1 - indicator-base scale (section value 2 degrees); 12.2 - perpendicular $\operatorname{rod}(\varnothing 4 \mathrm{~mm})$ for the plane of the scale

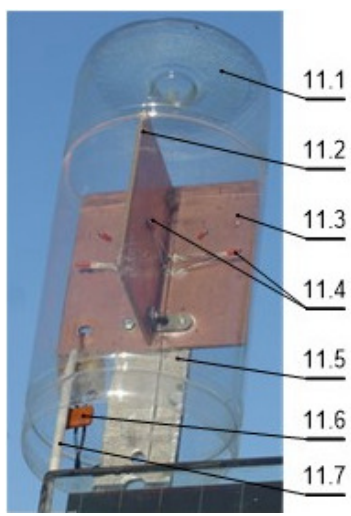

Fig. 5. Solar sensor: 11.2 - partition; 11.3 - base; 11.4 - infrared radiationdiodes (3L107B), six pcs. (three oneach side); 11.5 - mounting plates; 11.6 - fault blocking capacitor $(0.5 \mu \mathrm{F}) ; 11.7$ - current output

Equipment studies. The study of the facility in question was made in 2017, from June to October, in order to record the production capacity of the solar and solar panels, to calculate and graphically display the production capacities, calculate the quantities of energy produced, determine the most important parameters, register and analyze equipment failures, shortcomings. The datarecording scheme used to determine the power produced by both solar panels is given in Fig.6.

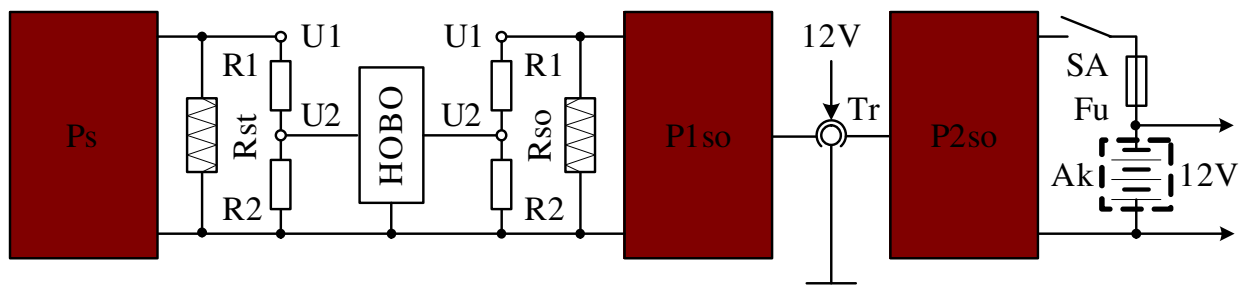

Fig. 6. Scheme for data measuring: Ps - stationary fixed solar panel (GS-50, a-Si); P1so, P2so - sun oriented panels (GS-50, a-Si); Rst, Rso - stationary fixed and sun oriented panels electrical load impedance $(\mathrm{Rst}=48.8 \Omega ; \mathrm{Rso}=48.2 \Omega) ; \mathrm{R} 1, \mathrm{R} 2-$ voltage dividers; U1, U2 - voltage; HOBO - data logger HOBO-H08-007-02; Tr - sun's tracking mechanism; Ak - battery, 12V, 55Ah;SA - switch;

$$
\mathrm{Fu} \text { - fuse SA - switch; Fu - fuse }
$$

According to the passport data, the solar panels GS-50 idle voltage VOC $=62 \mathrm{~V}$. The logger HOBO-H08-007-02, for which the voltage rating is $2.5 \mathrm{~V}$, is used to record the voltage (power) produced by the panel. Therefore, voltage dividers R1, R2 are used to match the voltage produced by the panel with the data recorder voltage. In the studies photovoltaic panels GS-50 (a-Si) have been used before testing the panels under identical conditions (at a sunny day lunch, when the solar radiation dropped to the surface of the panels in the normal direction). It has been found that the 
stationary fixed panel's power output is 1.16 times higher than the sun tracking panels. Therefore, when processing the data, the sun tracking panel's power was multiplied by 1.16 .

\section{Results and discussion}

When performing the settings of the parameters of the equipment, measurements (timings) and calculations, the PV panel technical data were used; the most important parameters of the device are summarized in Table 1. HOBO registered 12 solar panel power output as time functions, $P p=f(t)$ files. Each file is ten days long. Fig. 7 to Fig. 10 show the graphical and produced energy distribution functions of the solar panels generated by measurement and calculation ( $T a$ - airtemperature, Pst stationary PV panel power, Pso - sun-oriented PV panel power) [5; 6].

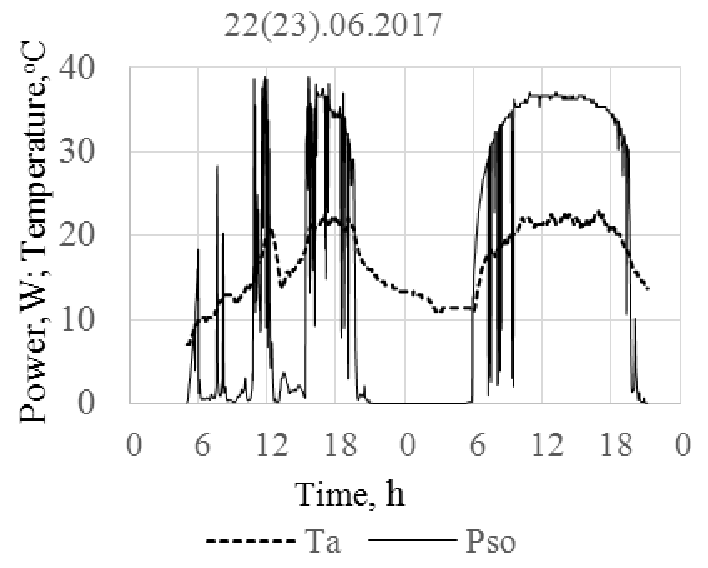

Fig. 7. PV panel P1so power

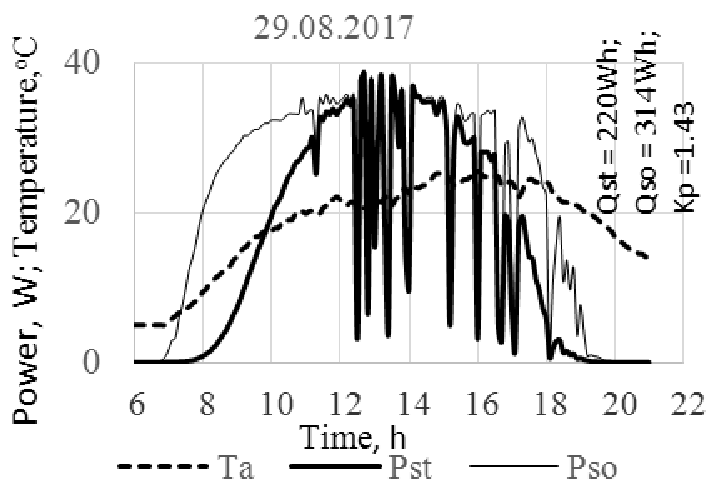

Fig. 9. PV panel P1so power and energy

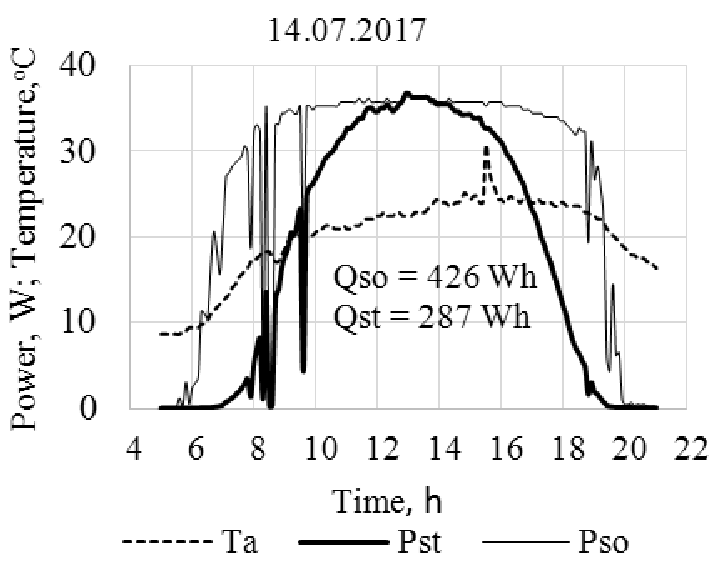

Fig. 8. PV panel P1so power and energy

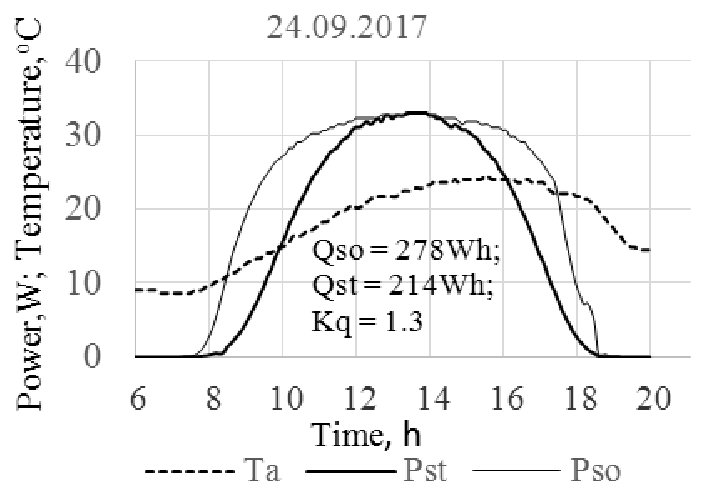

Fig. 10. PV panel P1so power and energy

In the course of the test, it has been observed that in cloudy time, when the sun's radiation has been screened by the cloud, and from the adjacent cloud (clouds) sufficiently strong reflected radiation falls to the panels, the device rotates and orientates the panels towards the reflected source. When exposed to the sun, the unit will turn the solar panels back to the sun. As observations and measurements show, during clear daytime, when the sun shines continuously, the device accuracy in the azimuthal plane, according to the indicator in Fig.4, is no worse than \pm 2 degrees. In clear days the panel rotational pulse duration is less than one second. On clear daytime and cloudy days without significant precipitation (Fig. 8), the device operates smoothly, if we do not take into account the delay in starting the morning hours associated with the cleaning time of the solar sensor (Fig. 4). As the lower part of the solar sensor lid is open, then during the rain the sensor's outside as well as inside is covered with dew and water droplets, causing the device not to function. Therefore, in order to improve the productivity of the equipment, the solar sensor must be in a sealed housing and from a material without droplets of water. The solar sensor's angle of detection is \pm 90 degrees, that is, six hours. If the sun does not shine during this time, then returning the panels to the east at night, on the next day in the afternoon the unit may stop working. Therefore, if the weather is cloudy, the night sensor has to be switched to return the panels in the southern direction during the night. When the 
weather is overcast all day, the equipment in question can lose its classical two-engine performance with a program or a satellite-controlled tracking, but it is more productive to produce in cloudy weather, collecting the radiation reflecting from clouds. The frequency at which the zenith angle is adjusted depends on the accuracy and time of the year. For example, if we accept the allowable radiation deviation up to $\pm 2.5^{\circ}$, then setting $21^{\circ}\left(+2.5^{\circ}\right.$ by the indicator, radiation shadow up $)$ at the beginning of the second decade of May, the device without moving can be operated until the first decade of August, which is 2.5 months. In order to maintain the same $\left( \pm 2.5^{\circ}\right)$ radiation in spring and in the autumn, that is, in March, April, August, September and October, the zenith angle setting of the device has to be changed twice a month. It should be noted that solar radiation deviation on the surface of the solar panel by $\pm 5^{\circ}$ from normal does not affect the panel's power output at all, since $\Delta P=\left(1-\cos 5^{\circ}\right)=0.004$.

\section{Conclusions}

1. There is manufactured and experimentally investigated a solar PV panel tracking device of one engine in two axes, where the motor of the rotating panels in the zenith plane has been replaced with the crank-angle mechanism, and the automatic operation of the device is performed by the solar and night sensors.

2. The solar panel installed on the PV equipment in the middle of summer produces 1.48 times more electricity than its stationary fixed analogue, but in September, 1.3 times more.

3. During the PV devise test, it has been found that, when the solar sensor is covered by a cloud, the system of solar panels can independently orient towards the reflected radiation from the cloud and thus collect the solar energy reflected from the clouds.

4. In order to achieve the accuracy of the orientation of the PV panels in the zenith plane of $\pm 2.5^{\circ}$, in mid-summer with one zenith angle adjustment the device can operate for 2.5 months, while in March, April, August, September and October the zenith angle must be revised twice a month.

5. To achieve high stability and performance of the device, the solar sensor has to be hermetically sealed in a transparent housing.

\section{References}

[1] Paulek V., Libra M. Solar energy. CUP, 2006, 153 p.

[2] Kancevica L., Putans H., Putans A., Ziemelis I. Analyze of meteorological parameters for development of solar collectors. Scientific Conference "Engineering for Rural Development". May 18- 19, 2006, Jelgava, Latvia, pp. 177-180.

[3] Харченко Н.В. Индивидуальные солнечные установки (Individual solar appliances). М. Энергоиздат, 1991, 208 с. (In Russian).

[4] Dual-Axis Solar Tracker for 4 panels ST44M2V4P for $1.0 \mathrm{kWp}$, [online][19.03.2018] Available at: http://www.solar-motors.com/gb/solar-tracker-2-axis-sm44m1v4p-w-backstr-for-4-pan-1-2kwp-i229.shtml

[5] Pandalons V., Iljins U.. Meteoroloǵija. Mācību līdzeklis bioloǵisko specialitāšu bakalauriem un magistriem (Meteorology. Training appliances for bachelor and master students of biological speciality), I dą̧a, LLU, Jelgava, 1999, 112 lpp. (In Latvian).

[6] Dukulis I. Aprēķini un datu grafiskais attēlojums (Programme Microsoft Excel 2000). Turība, Biznesaaugstskola, Rīga, 2002, 160 lpp. (In Latvian). 